veure amb el plagi sinó que implica reconèixer l'enriquiment que ens poden aportar els altres / les altres. D’aquest permanent joc de miralls neix la màgia d'aquest assaig de C. Riba, escrit de manera amena per arribar a tothom i acompanyar les persones interessades en la poesia i literatura de Marçal.

$\mathrm{Al}$ cap i a la fi, el llibre de $\mathrm{C}$. Riba s’ha de llegir com un indici més dels vincles que uneixen Maria-Mercè Marçal amb la generació actual de dones a la qual pertany C. Riba, i com una baula més en les "cartografies contra l'oblit".

Aquest primer volum el segueix un segon que porta el títol de Cos endins i s'estructura en tres grans blocs, tal com s'indica en el subtítol Maternitat, desig $i$ malaltia en l'obra de Maria-Mercè Marçal. Tenim el convenciment de que aquest nou assaig aconseguirà endinsar-nos en el text-cos marçalià.

SANDRINE RIBES

san.ribes@orange.fr

D.O.I.: 10.1344/105.000002163

Université Montpellier III

\title{
Legados de libertad. El arte feminista en la efervescencia democrática
}

María Laura Rosa

Buenos Aires, Editorial Biblos, 2014, 150 pp. ISBN: 978-98-7691-312-6

En la última década han aparecido nuevos análisis historiográficos sobre las prácticas del arte feministas y queer post ' 68 y su carácter rupturista frente a los relatos de la modernidad formalista canónica. Gracias a la aplicación de criterios metodológicos que beben de los estudios culturales, estudios de género y estudios visuales principalmente, ensayos como Legados de libertad constituyen valiosos documentos que recomponen los fragmentos de una genealogía del arte feminista no siempre validada por la institución (académica y museográfica). Así lo reivindica su autora, María Laura Rosa, que ofrece en 150 páginas un análisis pormenorizado del arte feminista en Buenos Aires durante la década de los ' 80 , gracias al complejo trabajo de recopilación de archivos y testimonios personales de aquel periodo.

El libro se reparte en cinco capítulos. El primero analiza el papel de la Unión Feminista Argentina (UFA) de la mano de la cineasta María Luis Bemberg, que participó en su consolidación. Se trata de una de las primeras agrupaciones del país en la que confluyeron ámbitos que sistemáticamente habían estado separados (técnico, económico, artístico, político, etc.). Pionera de la llamada segunda ola del feminismo argentino, la UFA introdujo en los ' 70 , aunque tímidamente, algunos de los planteamientos del feminismo anglosajón en los 
procesos de concienciación entorno a las relaciones de subordinación / poder que vivían las mujeres y a sus problemáticas locales. En 1976, la irrupción del golpe de Estado ejerció un férreo control sobre la sociedad argentina y, consecuentemente, entrañó la suspensión de la práctica feminista hasta el fin de la dictadura en 1980, año en que reaparecen nuevos actos y campañas en pos de la democratización del país y de los derechos sociales.

El segundo capítulo se centra en la fotógrafa y escritora Ilse Fusková, que escribió, tradujo (del feminismo norteamericano principalmente) y difundió un extenso trabajo teórico y visual entorno a la representación no heteronormativa del cuerpo y el deseo lesbiano "no sólo como una elección sexual sino como una opción de resistencia al patriarcado" (60). Para Fusková y su entorno, la urgencia por restituir las conquistas de las mujeres, alcanzadas en las décadas previas, fue central en el proceso de recuperación democrática en Argentina durante los ' 80 . Entre otras iniciativas, el impulso de nuevos movimientos y entidades autogestionadas como Lugar de Mujer (1983-1988) o el Grupo Feminista de Denuncia (1986-87), deben considerarse la punta de lanza de un activismo en el arte feminista local que influirá de forma decisiva en las generaciones posteriores.

La serie de exposiciones bajo el título Mitominas es abordada en el tercer y quinto capítulos. A diferencia de las prácticas de carácter más militante, Mitominas acogió una diversidad de posiciones, no siempre feministas, para una relectura de los mitos clásicos femeninos. "Más allá de la heterogeneidad de los trabajos y posiciones ideológicas, Mitominas 1 (1986) fue la primera exposición porteña que inauguró en democracia los debates y reflexiones sobre las construcciones de lo femenino" (92). En 1988, Mitominas 2. Los mitos de sangre reunió a doscientos participantes que activaron un programa de acciones en torno a las interpretaciones míticas de la sangre, la violencia de género y el sida, la sexualidad femenina y la maternidad. Finalmente, Mitominas 3. Cóleras de América concluye la serie en 1992, tomando la metáfora del “cólera” en respuesta a dos fenómenos que coinciden en tiempo y territorio: la celebración del quinto centenario del descubrimiento de América y el brote de cólera que reapareció en algunas zonas del país por la desatención de las instalaciones públicas y agua potable.

A modo de entreacto entre las Mitominas 1 y 2, el cuarto capítulo atiende al análisis de un proyecto colectivo creado por mujeres y hombres que también participaron en las exposiciones Mitominas. La exhibición Los espacios domésticos: del sótano al desván o El ama de casa y la locura consistía en una serie de instalaciones, fruto del cruce entre poesía, teatro y música que ocuparon la Galería de Arte Centro Cultural de San Martín en 1987. Tal como sugiere el título, el proyecto presentaba una lectura crítica - sin olvidar el uso del humor, la ironía, el sarcasmo y el absurdo como herramientas políticas-, sobre la asignación histórica de la mujer en el hogar, los conflictos domésticos, sus efectos 
en la formación de la subjetividad femenina y el impacto en la vida económica y comunitaria de las tareas reproductivas.

Sin duda, la lectura atenta que nos ofrece María Laura Rosa de las Mitominas reafirma su centralidad, en tanto en cuanto espeja ciertas cualidades de la práctica feminista de entonces hoy asumidas por el arte contemporáneo: el potencial colectivo frente a la idea legitimadora del genio creador individual; la reivindicación de las artes asociadas como "menores"; la disolución entre cultura de élite y cultura popular; la ruptura de las unidades de tiempo y espacio propias del cubo blanco como dispositivo de exposición normativo; la desmaterialización de lenguajes y medios (en su momento alternativos al dominio del formalismo moderno: la instalación, la performance y el videoarte); el carácter interdisciplinario y el pensamiento situacional.

Tampoco es baladí la revisión de las Mitominas en Legados de libertad si consideramos la evolución del feminismo activista y políticamente consciente al llamado "feminismo de estado", que conllevó una institucionalización de las manifestaciones feministas y su progresiva desideologización. Este fenómeno, que en España tuvo lugar a partir de 1983 con la creación del Instituto de la Mujer, comienza en Argentina en los años 90 cuando se constituyen diferentes secretarías e institutos para la mujer y se oficializan los estudios de género en el ámbito universitario (133). Por otra parte, el impacto de la globalización en la cultura de los '90 por el debate postmoderno desató la apertura de nuevos centros de exhibición, la aparición de coleccionistas locales, la efervescencia de premios, etc., con el fin de equiparar la escena artística de Argentina con las tendencias que imperaban a nivel internacional. Una de las causas de este desarrollo será la emergencia de un arte femenino más cercano a la corrección política, fácilmente integrable en el mercado, por la disolución y olvido de las posiciones más reivindicativas de los años ' 80 .

Legados de libertad es una investigación importante para entender el marco en el que se desarrollaron las prácticas feministas de segunda generación en el campo del arte de la ciudad de Buenos Aires. Si bien es legítimo reconocer en el libro el legado de muchos de los discursos que han atravesado los feminismos hegemónicos de occidente en la segunda mitad del siglo XX, María Laura Rosa traza con detalle cómo éstos fueron (y siguen siendo) interpretados y singularizados por las mujeres artistas para desactivar la visión canónica y patriarcal impuesta por la historia nacional argentina.

MonTse Romaní

nonplaces@gmail.com 